\title{
H istória, antropologia e a cultura afro-americana: o legado da escravidão
}

\author{
RAFAEL DE BIVAR MAR QUESE
}

A verdade inescapável no estudo da Afro-América é a humanidade dos oprimidos e a desumanidade dos sistemas que os oprimiram.

$M$ as nem todos os sistemas escravagistas oprimiram igualmente todos os escravos, e nem todos os escravos lidaram da mesma maneira com sua opressão ${ }^{1}$.

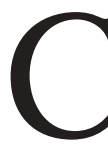

om esSAS palavras Sidney Mintz e Richard Price fecharam seu livro 0 nascimento da cultura afro-americana: uma perspectiva antropológica, recém-lançado no Brasil. M intz e Price são dois renomados antropológos norte-americanos, especialistas respectivamente no estudo das sociedades do Caribe e do Suriname, cuja produção teve e ainda tem grande repercussão nas pesquisas sobre a escravidão e as culturas negras nas Américas. Alguns dos pressupostos centrais do livro foram bem salientados na passagem acima: a necessidade da compreensão integrada da história da A mérica e da África, a importância da comparação entre os diferentes sistemas escravistas do N ovo M undo, o papel dos escravos

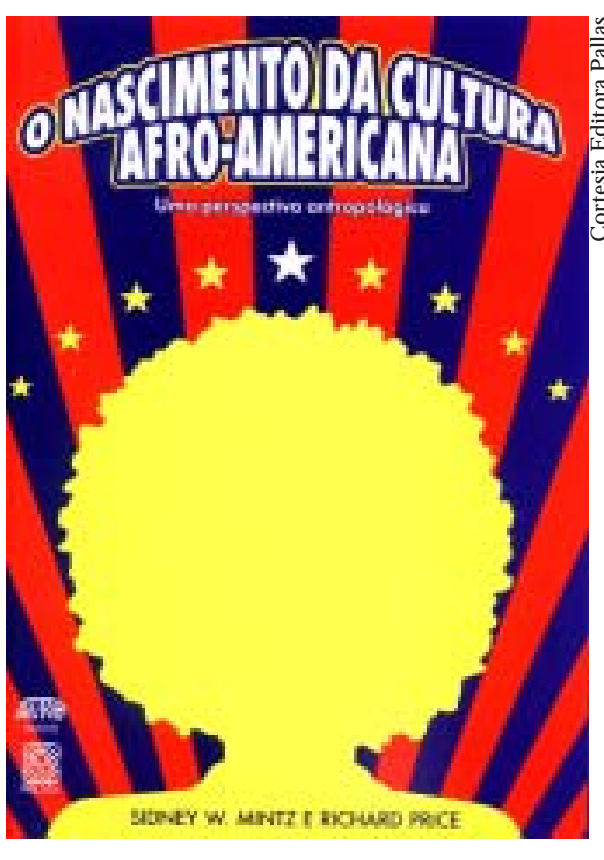
como sujeitos históricos para a conformação dos sistemas em que viviam. Esses pressupostos, por sua vez, tinham um objetivo preciso: dialogando com uma longa vertente de estudos sobre a cultura afro-americana, M intz e Price pretendiam discutir criticamente as teses sobre as culturas escravas nas Américas que as concebiam como totalmente "aculturadas" ou estritamente "africanas".

D e fato, quando saiu a primeira edição do livro em 1976 (baseada em uma conferência que M intz e Price proferiram em 1973), os estudos sobre a questão continuavam polarizados em posições marcadamente distintas. Por um lado, havia os que adotavam a "tese da catástrofe" cultural que a escravidão teria representado para os africanos e seus descendentes nas Américas. Essa seria a história de "um longo desastre, uma crônica de horrores na qual os negros experimentaram todas as formas concebíveis de exploração, humilhação e sofrimento nas mãos de seus 
opressores brancos"; de acordo com essa visão, o negro teria sido despojado culturalmente de suas raízes africanas, e "forçado a se aculturar ao modo de vida e pensamento de seu opressor branco". Dentre os formuladores da tese da catástrofe cultural, estavam o sociólogo norte-americano Franklin Frazier, o antropólogo francês Roger Bastide e o historiador norte-americano Stanley E Ikins. Por outro lado, os estudiosos que defendiam a "tese da sobrevivência" das formas culturais africanas no N ovo M undo postulavam a capacidade que os negros tiveram para sobreviver à opressão branca, mantendo relativamente intactas suas expressões culturais trazidas da África. 0 nome mais destacado, aqui, era o do antropólogo norte-americano M elville H erskovits².

C abe salientar que toda essa produção se deu entre as décadas de 1930 e 1960. Com efeito, o debate entre Frazier e H erskovits teve início ainda nos anos de 1930, ao passo que as principais publicações de Bastide e E Ikins vieram a lume na década de 1950. A quantidade de títulos sobre o assunto, contudo, ainda era restrito. $\mathrm{N}$ a década seguinte, houve um notável incremento nos estudos sobre 0 passado escravista nas Américas. Como há muito assinalado, o boom da historiografia sobre a escravidão verificado a partir dos anos de 1960 foi uma resposta direta a questões sociais e políticas como a campanha pelos direitos civis nos Estados U nidos, a luta pela independência dos países africanos ou a luta antiimperialista no Terceiro $\mathrm{M}_{\text {undo }}{ }^{3}$.

$\mathrm{N}$ essa virada, a tese da sobrevivência tomou a dianteira. $\mathrm{O}$ s pesquisadorese o movimento negro reagiram em especial às visões mais extremadas do catastrofismo, como a de Stanley Elkins, que negavam aos escravos e aos afro-descententes qualquer agência na construção de seu devir ${ }^{4}$. A reação, no entanto, veio muito mais da história que da antropologia. A té fins dos anos de 1960, poucos foram os antropólogos que trataram do passado escravista dos afro-descendentes no N ovo M undo, e, mesmo os que o fizeram - excetuando-se os trabalhos inovadores de $\mathrm{H}$ erskovits - tendiam a nivelar a trajetória do escravismo nas Américas em um passado anistórico, encarando-o unicamente sob o prisma da continuidade em direção ao presente.

O silêncio a respeito da escravidão no campo da antropologia, sugere Igor Kopytoff, derivou do próprio caráter que esse saber adquiriu entre as décadas de 1920 e 1960. A ênfase no trabal ho de campo, além de restringir o arco das sociedades que o pesquisador poderia investigar, levou a uma crescente indiferença pela história entre os antropólogos, mesmo quando o passado da sociedade sob análise pudesse ser recomposto. Como escreve Kopytoff, "uma certa arrogância a respeito da superioridade da percepção antropológica tornou fácil desqualificar os registros dos viajantes coevos, administradores coloniais e missionários como tendenciosos e ingênuos" ${ }^{5}$. Por todas essas razões, as simplificações a respeito do passado afro-americano viraram moeda corrente, e, não por acaso, alguns antropólogos começaram a sentir, em fins dos anos de 1960, a necessidade de uma abordagem histórica substantiva para melhor compreender o presente afro-americano ${ }^{6}$. 
M as os problemas não eram exclusivos do campo da antropologia. 0 peso crescente da tese da sobrevivência estava conduzindo a alguns impasses interpretativos, como o escamoteamento do impacto que a escravidão teve para a conformação da cultura afro-americana. D o mesmo modo, a escrita da história com base nos marcos territoriais dos Estados nacionais levava os historiadores a verem a experiência afro-americana de forma isolada, não-comparativa, e a natureza das fontes legadas pel os escravos e seus descendentes (em geral restritas à cultura material e à tradição oral) dificultava o trabalho de investigação. Portanto, o quadro geral dos estudos sobre a cultura afro-americana no começo da década de 1970 poderia ser resumido da seguinte forma: os antropólogos davam lugar secundário à história como ferramenta para examinar o presente afro-americano, enquanto os historiadores - quando não comprometidos politicamente a provar a tese da sobrevivência a qualquer custo - sentiam a falta de um instrumental analítico adequado para avançar na questão ${ }^{7}$.

O ensaio de M intz ePrice, redigido entre 1972 e 1973, propôsuma solução clara para o impasse, e com esse espírito foi concebido. Afinal, como esclarecem no novo prefácio para a edição de 1992, o livro

pretendeu ser uma profissão de fé e um manual. Estávamos inquietos com al gumas polarizações que vinham despontando nos estudos afro-americanos. [...] Assim, concentramo-nos nas estratégias ou abordagens do estudo do passado afro-americano, em vez de apresentar os resultados atualizados desses estudos, na esperança de incentivar historiadores e outros pesquisadores que estivessem ingressando nesse campo a empregarem modelos conceituais que ficassem plenamente à altura da complexidade de seu tema ${ }^{8}$.

No que consiste a proposta? Em primeiro lugar, a idéia de que sem 0 cruzamento da história com a antropologia é impossível compreender devidamente as culturas afro-americanas. Tal cruzamento deve contemplar sobretudo os métodos desses dois campos do saber, englobando a comparação, o uso de fontes pouco exploradas e de novas técnicas para analisá-las. Em sua conclusão, $M$ intz e Price deixam claro que

a postura teórica que adotamos neste ensaio é que o passado deve ser visto como a circunstância condicionadora do presente. $\mathrm{N}$ ão cremos que o presente possa ser "compreendido" - no sentido de se explicarem as relações entre diferentes formas institucionais contemporâneas - sem referência ao passado 9 .

O segundo elemento da proposta consiste em destacar o peso do escravismo para a compreensão das culturas afro-americanas, em especial o papel que os escravos desempenharam na criação de novos valores, instituições e formas culturais. O s autores ressaltam que as condições do povoamento europeu e africano do $\mathrm{N}$ ovo M undo foram profundamente distintas: afora o fato de os europeus portarem uma cultura relativamente homogênea enquanto os africanos carregaram 
consigo "heranças culturais relativamente variadas", o statusde ambos os grupos diferiu radicalmente. I sto, por sua vez, teve impacto decisivo na continuidade ou no reordenamento cultural, pois "os sistemas legais, os sistemas econômicos, os sistemas de ensino, as instituições religiosas e muitas outras coisas puderam ser estabelecidas e desenvolvidas pelos europeus através de meios que não estavam ao alcance dos escravos" ${ }^{10}$. Sendo assim, toda a ação escrava no sentido da criação de uma cultura própria teve que remar contra a corrente do poder escravista.

Q uestionando a idéia da unidade cultural da África ocidental apresentada por $\mathrm{H}$ erskovits, $\mathrm{M}$ intz e Price defendem a hipótese de que, no nível das formas manifestas e crenças explícitas, as culturas africanas das regiões que abasteceram o tráfico negreiro transatlântico foram marcadas por grande heterogeneidade. O s autores não negam a existência de uma herança cultural comum aos africanos, mas afirmam que ela teria de ser observada em um outro nível, o dos "princípios gramaticais inconscientes" e das "orientações cognitivas", e não poderia ser automaticamente associada a manifestações culturais explícitas, visto que estas estariam sempre diretamente ligadas' às formas institucionais que as articulavam. A natureza do fluxo migratório dos africanos para a América representou enorme obstáculo para a transposição cultural simples, pois as instituições que conferiam organicidade às diversas culturas africanas não puderam ser trazidas nos navios negreiros. O s cativos tiveram que criá-las nas Américas por meio de sua própria agência, mas sempre com base naqueles "princípios gramaticais" mais profundos.

As constrições da escravidão devem ser levadas em conta em qualquer investigação sobre a formação da cultura afro-americana. Com efeito, a relação escravista era profundamente assimétrica, com uma enorme concentração de poder nas mãos dos senhores. $\mathrm{N}$ os primeiros tempos, dadas essas constrições, apenas alguns tipos de instituição puderam ser desenvolvidos pelos escravos, mas ainda na travessia atlântica os africanos teriam começado a estabelecer os laços de novas redes de so ciabilidade, base para as futuras formações culturais. Progressivamente, a lógica de funcionamento do sistema de plantation e a resistência escrava aos ditames senhoriais abriram espaço para a elaboração de uma cultura afro-americana autônoma. As instituições culturais criadas pelos escravos nos embates contra seus donos assumiram sua forma dentro dos parâmetros do monopólio senhorial do poder, mas eram separadas das instituições senhoriais. A demais, a heterogeneidade cultural forçou os escravos a reinventarem seus compromissos no $\mathrm{N}$ ovo $M$ undo, imprimindo às primeiras culturas afro-americanas grande dinamismo. Tratar-se-iam de quadros culturais abertos à novidade, mas sempre informados pelas orientações cognitivas mais profundas trazidas da África.

Após a primeira edição de 0 nascimento da cultura afro-americana, uma parte substantiva da historiografia sobre a escravidão nas A méricas valeu-se dos métodos e das hipóteses de pesquisa apresentados por M intz e Price, ainda que algumas de suas proposições tenham sido criticadas $^{11}$. D e todo modo, trata-se de um livro que marcou época e que mantém sua atualidade. No caso da historiografia 
sobre a escravidão brasileira, isso pode ser facilmente observado pela influência que exerceu em algumas das obras mais importantes publicadas nas últimas duas décadas, e que abordaram temas variad os como as expressões religiosas e festivas dos africanos e seus descendentes, as estruturas de parentesco, a cosmovisão e a rebeldia escravas, dentre outros ${ }^{12}$. A publicação no B rasil desse clássico dos estudos afro-americanos, enfim, é mais que bem-vinda.

\section{N otas}

1 Sidney M intz e Richard Price, 0 nascimento da cultura A fro-A mericana. U ma per spectiva antropológica, E dição revista de 1992, trad. Vera Ribeiro, Rio deJ aneiro, Pallas-U niversidade C ândido M endes, 2003, p.113.

2 A citação é de O rlando Patterson, "R ethinking Black H istory" , H arvard Educational R eview. 41 (3): 297-315, 1971, p. 299, que propõe a classificação "tese da catástrofe" e "tese da sobrevivência". O utro balanço útil sobre a questão e que analisa de forma integrada a produção brasileira e norte-americana pode ser encontrado em Robert Slenes, $\mathrm{N}$ a senzala, uma flor. Esperançaserecordaçõesna for mação da família escrava - Brasil sudeste, século XIX, Rio de Janeiro, N ova Fronteira, 1999, pp. 28-43.

3 Ver, a respeito, os ensaios de David Brion Davis ("Slavery and the Post-War II H istorians") e M ichael Banton ("1960: A Turning Point in the Study of Race Relations") em Sidney M intz (ed.), Slaver $\mathrm{y}$, Colonialism, and R acism, N ew York, W. W. Norton, 1974.

4 Cf. O. Patterson, op.cit., p. 300; Peter H. Wood, "I did the Best I C ould for y ay': The Study of Early Black H istory during the Second Reconstruction, 1960 to 1976", The William and Mary Quarterly. 3a série. 35 (2): 185-225, 1978.

5 I. Kopytoff, "Slavery", A nnual R eview of A nthropology, 11: 207-230, 1982, p. 213.

6 Ver, por exemplo, o ensaio deJ ohn F. Szwed, "An American Anthropological D ilemma: The Politics of Afro-American Culture", em Dell H ymes (ed.), R einventing A nthropology. ( 1 a ed: 1969). N ew York, Vintage, 1974.

7 Essa recomposição do quadro dos estudos sobre o passado afro-americano baseia-se em 0. Patterson, op.cit., pp. 310-313. Aliás, vale lembrar que Patterson concluiu seu ensaio (pp. 313-315) com uma proposta de estudos históricos comparativos que deveriam recorrer à antropologia, algo muito semelhante ao programa proposto por M intz e Price em 1973.

8 S. M intz e R. Price, op. cit., p. 7.

9 Idem, p. 113.

10 Idem, pp. 21-22.

11D entre as críticas, assoma o trabal ho do africanista J ohn Thornton, que vem questionando com base em extensas pesquisas as hipóteses a respeito da heterogeneidade cultural africana e do impacto negativo do tráfico negreiro e da escravização para a transmissão cultural entre África e América. Ver J. K. Thornton, A Á frica eosafricanos 
na formação do mundo atlântico (1400-1800) (trad. port.), Rio de J aneiro, C ampus/ Elsivier, 2004, pp. 253-311.

12 Sem qualquer pretensão de ser exaustivo, cabe destacar a importância do modelo de M intz e Price para os seguintes trabalhos: R. Slenes, op. cit.; João J osé R eis, R ebelião escrava no Brasil. A história do levante dos Malês em 1835, Ed. revista, São Paulo, Companhia das Letras, 2003; Sidney Chalhoub,Visões da liberdade. U ma história dasúltimasdécadasda escravidão na C orte, São Paulo, Companhia das L etras, 1990; M arina de Mello e Souza, Reis N egros no Brasil Escravista. H istória da Festa de Coroação deR ei Congo,Belo H orizonte, Ed. U FM G, 2002.

Resumo - A ReCEnte edição no Brasil do livro de Sidney M intz e Richard Price, O nascimento da cultura afro-americana: uma perspectiva antropológica, publicado originalmente em inglês em 1976, é uma boa oportunidade para se efetuar um balanço suscinto das discussões sobre o papel da história e antropologia no estudo das culturas afroamericanas.

Abstract - THE brazilian edition of TheBirth of A frican-A merican Culture: A n A nthropological Perspective, originally published by Sidney M intz and Richard Price in 1976, is a good opportunity to review briefly the academic discussions about the role of history and anthropology in the study of african-american cultures.

R afael de Bivar Marquese é professor do D epartamento de $\mathrm{H}$ istória da Faculdade de Filosofia, L etras e Ciências H umanas da U SP.

Texto recebido e aceito para publicação em 27 de fevereiro de 2004. 